\title{
Impact of the integration of photovoltaic installations in rural grids: case study
}

\author{
O. Azurza ${ }^{1}$, I. Zubia ${ }^{1}$, J.X. Ostolaza ${ }^{2}$, L.A. Leturiondo ${ }^{3}$ and A. Lazkano ${ }^{3}$ \\ ${ }^{1}$ Department of Electrical Engineering \\ Escuela Universitaria Politécnica, University of the Basque Country UPV/EHU \\ Plaza de Europa 1- 20018 Donostia-San Sebastián (Spain) \\ Phone/Fax number:+0034943 01 8594/+ 34943 017130, e-mail: olatz.azurza@ehu.es, itziar.zubia@ehu.es \\ ${ }^{2}$ Department of Systems Engineering and Control \\ Escuela Universitaria Politécnica, University of the Basque Country UPV/EHU \\ Plaza de Europa 1- 20018 Donostia-San Sebastián (Spain) \\ Phone/Fax number:+0034 943 018678/+ 34943 017130, e-mail: xabier.ostolaza@ehu.es \\ ${ }^{3}$ Department of Communications Engineering \\ Faculty of Engineering, University of the Basque Country UPV/EHU \\ Alameda Urquijo, s/n - 48013 Bilbao (Spain) \\ Phone number: +34 94601 4143, e-mail: luisalberto.leturiondo@ehu.es, andoni.lazkano@ehu.es
}

\begin{abstract}
This work studies the impact of the photovoltaic installation in a rural village of the Pyrenean region of Spain. Based on real data of electricity consumption a PV generation system has been designed and its effect in the distribution power losses and the voltage profile are analysed. As a second step, a storage system has been added to the PV system and the optimal dimension of the hybrid system has been calculated in order to reduce the peak value of the demanded power.
\end{abstract}

\section{Key words}

Rural electrification, distributed generation, smart grid, power measurement, power quality.

\section{Introduction}

With 31.1 GW added globally in 2012 - roughly the same figure as was added in the 2011 boom year - the world has passed the $100 \mathrm{GW}$ mark in cumulative installed photovoltaic capacity [1]. Furthermore, IEA PV roadmap envisions that by 2050, PV will provide $11 \%$ of global electricity production (4500 TWh per year), corresponding to $3.000 \mathrm{GW}$ of cumulative installed PV capacity. In addition to contributing to significant greenhouse gas emission reductions, this level of PV will deliver substantial benefits in terms of the security of energy supply and socio-economic development [2]. In this line, solar photovoltaic systems have shown their potential in rural electrification projects around the world, especially concerning Solar Home Systems [3].

This paper is part of a general project which goal is to demonstrate the feasibility of self-generation of renewable energy facilities in rural areas, based on the concept of a microgrid.

In this paper the impact of a PV + storage system implemented in a rural distribution system is presented. Once the rural location has been chosen the methodology is based on the following phases:

- Load characterization

- Dimensioning of the PV installation

- Dimensioning of the storage system

- Impact evaluation on electric losses and voltage profile.

\section{Load characterization}

The place selected to the study of rural microgrids is the Valley of Salazar, a valley in the east of the Foral Community of Navarre in Spain. The Sierra de Abodi, part of the Western Pyrenees, forms the natural boundary in the north.

The first step towards the design of the PV installation is the knowledge of the power demand of the emplacement and the initial condition of the feeder without PV. In this sense, with the collaboration of Iberdrola Distribucion S.A. a measurement campaign has been done in two points of the valley.

During the month of September 2012 three phase voltages and currents have been recorded simultaneously both at the head of the valley and the village located at the end of the valley. The recording equipment developed by the research group GSC of the University of the Basque 
Country (UPV/EHU) consists of three subsystems: Signal conditioning system (SAC-2); data acquisition system (NI USB-6281) and the control system (SARPE v4.0).

The substation located at the head of the valley (in the village of Ustes) consists on a 5 MVA 66/22 kV transformer with delta-wye configuration. After a distribution line of $17 \mathrm{~km}$, the village of Ezcaroz is fed by a delta-wye grounded transformer of $630 \mathrm{kVA}$ and 20 $\mathrm{kV} / 400 \mathrm{~V}$. The transformer feds 130 customers giving a total contracted power of $600 \mathrm{~kW}$.

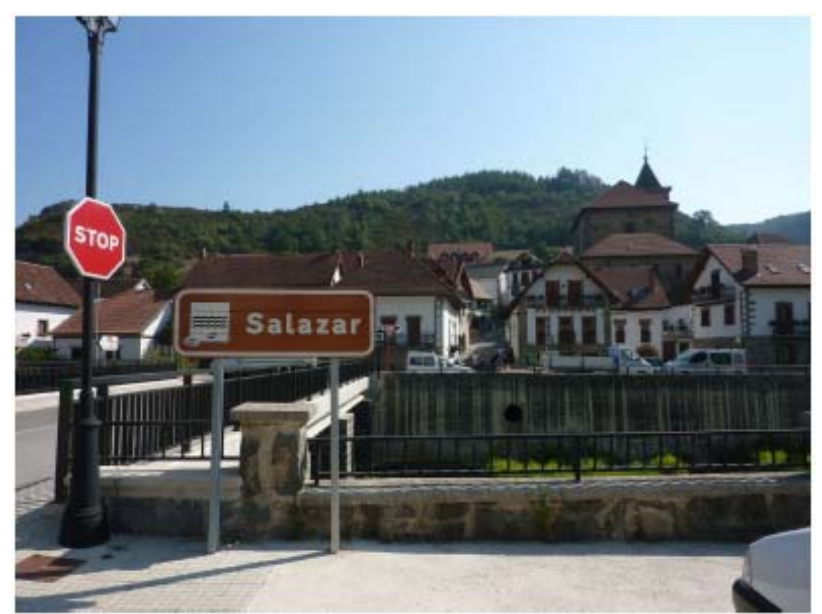

Fig. 1. General view of Ezcaroz, home of the Board of Salazar Valley.

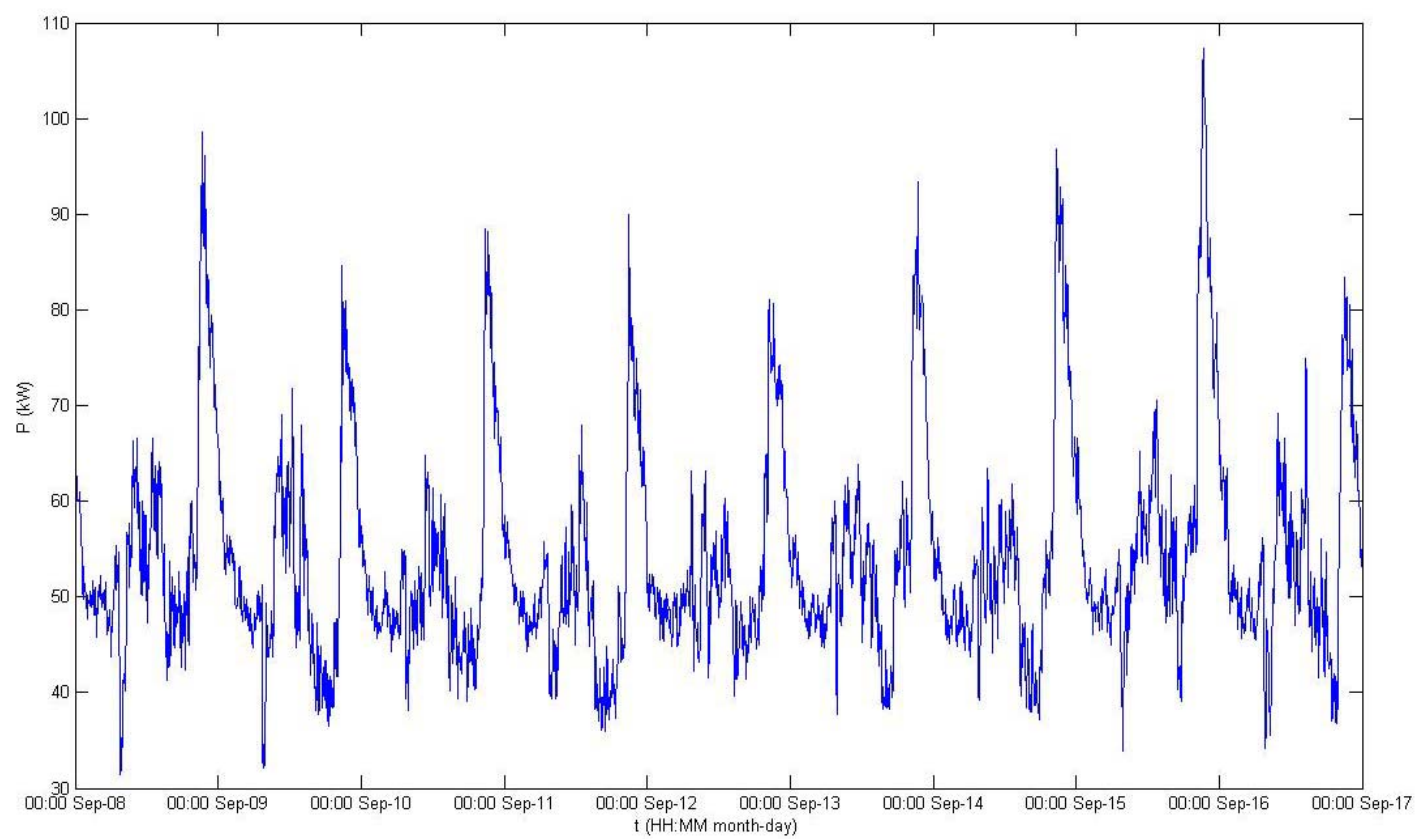

Fig. 2. Power demand of Ezcaroz registered from 0:00:00 of 8 September to 23:90:90 16 September 2013. .

Fig 2. Shows the power demand of Ezcaroz from 0:00:00 of 8 September to 16 September 2013. The curve shows a typical residential daily load curve with a minimum load at 4:00 and a peak load at 22:00. It can also be observed that the peak load increases on Friday and Saturday. It is thought that this increment is due to the effect of rural tourism and the affluence to the secondary residence on weekends.

Iberdrola Distribucion S.A. also provided the voltage, current, active and reactive power data from 1 November 2012 to 5 February 2013. According to data registered by the Institute of Meteorology of Navarra, the minimum temperature in the region was $-5{ }^{\circ} \mathrm{C}$ in December. However, the power demand has not grown significantly during that time, so it can be assumed that the heating of the village is not based on electricity.
Fig 3. shows the daily evolution of the RMS value of the currents. It can be observed that all three phases have not the same value and, actually, the power demand is not equilibrated between phases.

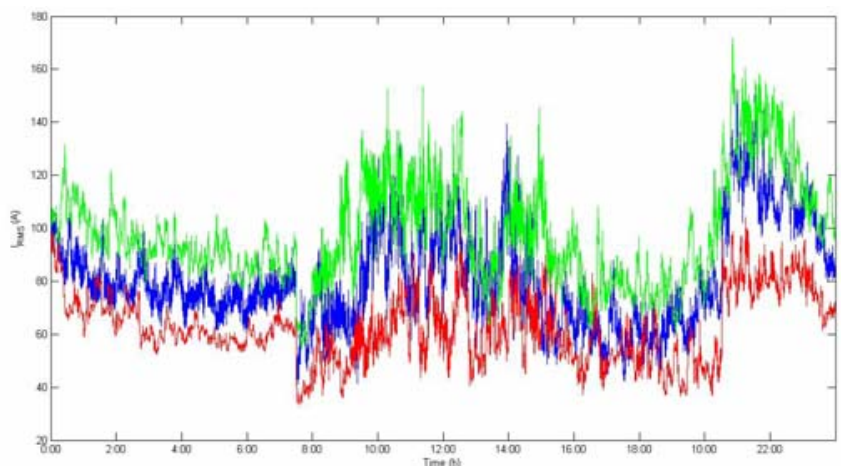

Fig. 3. Current RMS values at the transformer of Ezcaroz 


\section{Design and optimization of the PV installation}

The price of solar photovoltaic cells has dropped 99\% in the past quarter century. So in an increasing number of markets around the country, solar is at or very close to grid parity [4]. In this context, photovoltaic based electrical self-supply is considered to the village of Ezcaroz in Spain.

The objective of the present work is to optimize the size of the PV installation from an economic point of view. Based on the price of the last-resource tariffs in Spain and the price per installed $\mathrm{kWp}$ the most cost-effective solution will be calculated [5].

The power generated by the PV installation in Ezcaroz (42 5319 '' $\mathrm{N} 1^{\circ} 5$ '47' 'W, $742 \mathrm{~m}$ altitude) has been simulated in Simulink/MATLAB with the model proposed in [6]. The real temperature of 8-17 September 2012 and daily irradiance values obtained from Photovoltaic Geographical Information System (PVGIS) has been used.

With the simulation results mentioned above and recorded real data of Ezcaroz the weekly cost for electricity has been minimized. The cost includes the price of the PV installation, the cost of the electricity consumed during the week and the cost of the contracted power [7]. The equation to be solved is defined as follows:

$\min _{P_{P V}^{N \text { Nom }}}\left(P_{P V}^{N o m} \cdot c_{V P}+P_{\text {Contr }} \cdot c_{C o n t r}+\sum c_{i}\left(P_{d i}-P_{P V i} \cdot P_{P V}^{N o m}\right)\right)(1)$

where, $P_{P V}^{N o m}$ is the size of the $\mathrm{PV}$ installation to be optimized, $\mathrm{C}_{\mathrm{VP}}$ is the specific price of the installed $\mathrm{kWp}$, $P_{\text {Contr }}$ is the contracted power, $\mathrm{C}_{\text {Contr }}$ is the price of contracted power, $\mathrm{C}_{i}$ is the price of the last-resource tariff, $P_{d i}$ is the demanded power, and, finally $P_{P V i}$ is the PV power generated by a $1 \mathrm{kWp}$ installation.

The Spanish Electric Law Ley 24/2013, of 26th December 2013 [8] has modified the electric system of Spain but the net balance of self-generation has not been included in it. Self-generation net balance means that the owner consumes the self-generated electricity and injects the exceeding power to the network, so as he does not pay for the equivalent power consumed when his has a lack of electricity. Due to the fact that when the net balance is not considered the exceeding power generated by the PV system is not refunded, in equation (1) it has been assumed that the exceeding power is not injected to the network.

Fig 4. shows the variation of the cost with the size of the PV system from 8-14 September. It can be observed that the PV system that minimizes the cost is $120 \mathrm{kWp}$. In this point it must be noted that the maximum generated power during the month of September for a photovoltaic installation in zone I of Spain is half the installed capacity, so the optimal size is coherent with the midday demand.
From the definition of the cost of the electricity per week of equation (1) the initial value is $17.08 €$ for each owner and reduces to $15.02 €$ in the case of having the PV system, including its amortization.

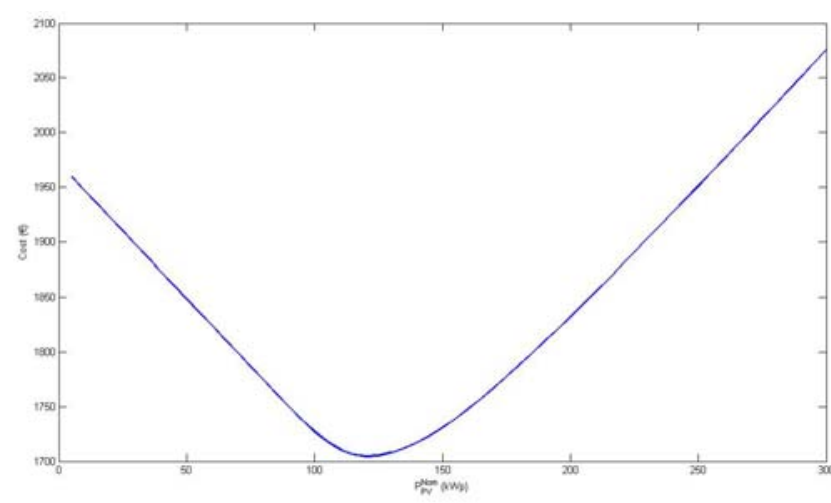

Fig. 4. Cost of the electricity for different nominal values of the PV installation

\section{A. Impact of the PV installation}

The interest of the current work is to assess the most common impacts caused by the interconnection of PV in the village of Ezcaroz: variation of feeder voltage profile, active and reactive power flow and distribution losses [9],[10],[11].

In this study it has been assumed that each consumer has PV panels on the roof, so as no additional area for power generation is required. In this way, once the total installed PV power has been calculated, it has been assumed that the PV generation of each phase is related with the proportion of the demanded power of each phase before the installation of the PV system.

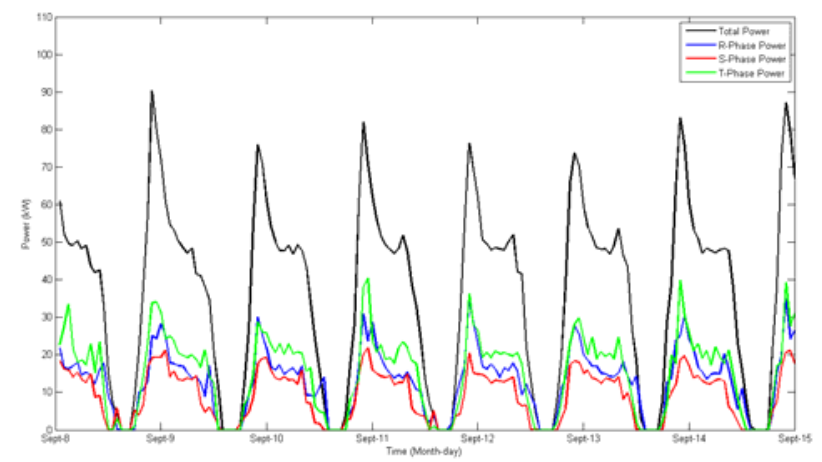

Fig. 5. Total and per-phase power demanded with PV system

Fig. 5 shows the evolution of the new demanded threephase power and the demanded power of each phase. It can be observed that from 15:00-17:00 the power consumed by the distribution system is zero, but the 21:00 peak demand does not vary

With the PV system designed above several scenarios has been analysed: the behaviour during peak demand and the possible overvoltage in case of minimal power demand. In both cases, due to the value of the Equivalent Thevenin Impedance of the place, the PV system does not disturb the voltage RMS values significantly, and the 
specifications of Power Quality [12] are accomplished at the bus of Ezcaroz.

In the other hand, power loses before the installations of the photovoltaic system were about $0.02 \%-0.01 \%-0.03 \%$ in phases R-S-T, respectively and reduces to the half of the previous value after the installation of the PV system.

In view of the technical impact and the total cost it can be said that the installation of PV systems is very well suited so as to complement the electric power fed by the network in this village.

Nevertheless, keeping on mind that the hourly PV generation does not match with the maximum power demand, the cost analysis of a storage system will be developed, to reduce its value with the exceeding power of midday.

\section{Design and optimization of the PV installation with storage systems}

The analysis presented in this section is a theoretical analysis without practical consequences, due to the fact that power storage is not allowed in Spain. The RD $1699 / 2011$ that regulates the self-consumption states that in the generating circuit until measuring equipment it may not be interleaved any generating element other than the authorized facility or accumulation [13]. On the contrary, German government has launched subsidies to finance storage systems and it is expected that they will reduce the average 20-year cost of a PV system with storage to $10 \%$ less than the system without it [14]. In the same way, storage subsidies are also available in both Japan and California.

In this study, the definition of the cost equation is based on the supposition that the energy storage will reduce the demand peak value, but will also allow the reduction of the contracted power, reducing the electric bill of the owners.

In this case, the electricity cost has 3 variables to be kept in mind: the size of the PV panels and the storage system, and the contracted power. The equation to be solved is defined as follows:

$$
\begin{aligned}
& \min _{P_{P V}^{N o m}, E_{S T}^{N o m}}\left(P_{P V}^{N o m} \cdot c_{V P}+E_{S T}^{N o m} \cdot c_{S T}+P_{C o n t r} \cdot c_{C o n t r}+\right. \\
& \left.\sum c_{i}\left(P_{d i}-P_{P V i} \cdot P_{P V}^{N o m}+P_{S T}\right)\right)(2)
\end{aligned}
$$

where, $P_{P V}^{\text {Nom }}, E_{S T}^{\text {Nom }}, P_{\text {Contr }}$ are the size of the PV installation, the storage system, and the contracted power, respectively; $P_{d i}$ is the demanded power and $P_{P V i}$ is the generated power of $1 \mathrm{kWp} \mathrm{PV}$ installation; $\mathrm{C}_{\mathrm{VP}}$ is the specific price of the installed $\mathrm{kWp}, \mathrm{C}_{\mathrm{ST}}$ is the specific price of the stored $\mathrm{kWh}$ and, finally, $\mathrm{C}_{\mathrm{Contr}}$ is the price of contracted power.

Fig 6. shows the variation of the cost with the size of the PV system and the storage system from 8-14 September. The values that optimize the cost of the hybrid system are 211.47 kWp of PV and $336.35 \mathrm{kWh}$ of storage.

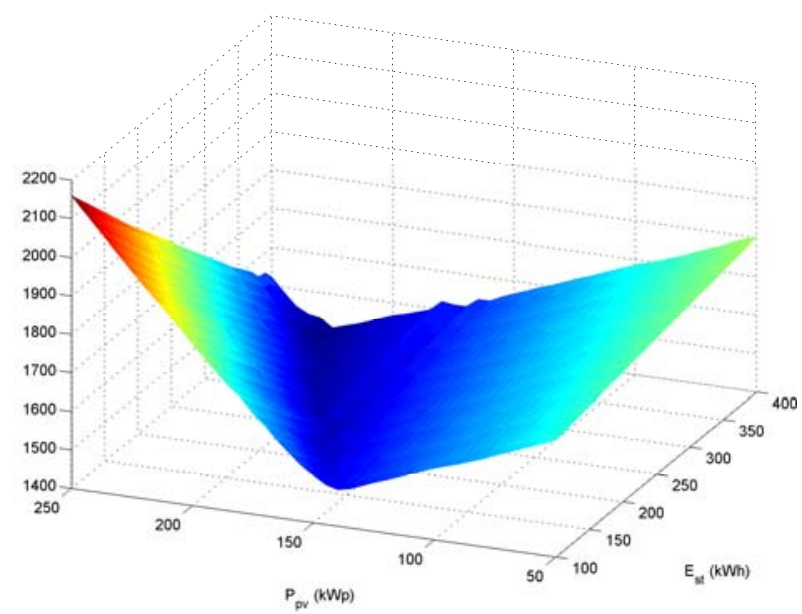

Fig. 6. Cost variation versus PV-system size and Stored energy.

With this hybrid PV+storage system the total cost of the electricity per week is $1417,49 €$, leading to $10.90 €$ per each consumer.

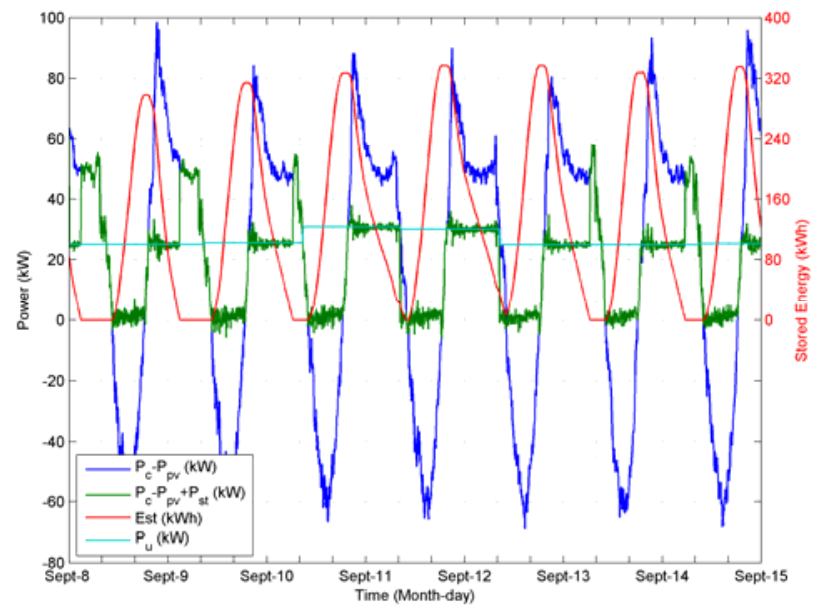

Fig. 7. Evolution of the new demanded power with PV and storage system.

Fig 7. Shows the evolution of the new demanded power when PV panels are installed (in blue). The negative values represent the exceeding power that will be stored at midday (in red) and will be used to reduce the peak demand in the evening.

The $\mathrm{P}_{\mathrm{u}}$ value at which starts the energy storage has been dynamically fitted in order to achieve the maximal use of the storage system. The daily evolution of this value can be observed in light blue in Fig. 7.

Finally, the evolution of the power demanded to the distribution network is shown in green colour. The power peak value with the designed $\mathrm{PV}+$ storage system is lower than $60 \mathrm{~kW}$, permitting to reduce the contracted power. 


\section{Conclusion}

In this paper two alternatives to complement the electric supply of a rural village are compared. The first one consists of each consumer installing PV panels on their own rooftops. The size of the PV system has been optimised and the impact on voltage profile has been analysed. Due to the characteristics of the distribution network, it has been concluded that the voltage satisfies Power Quality requirements even in the midday valley hours.

The second option is based on a PV + storage hybrid system. After optimizing the size of panels and the storage system a storage management algorithm has been developed. This solution allows reducing the contracted power and reduces the electricity cost of customers.

As a future work, the present study should be completed and extended to the case of extreme temperature conditions of summer and winter.

\section{Acknowledgement}

This work has been supported by the Government of the Basque Country within the research program Comunidad de Trabajo de los Pirineos as the project RURALGRID (CTP11-P09).

\section{References}

[1] M. Hall, "World passes $100 \mathrm{GW}$ installed PV capacity mark” http://www.pv-magazine.com.

[2] International Energy Agency IEA, "Technology Roadmap Solar photovoltaic energy”, 2010 (http://www.iea.org)

[3] B. van Campen, D. Guidi and G. Bes, "Solar photovoltaics for sustainable agriculture and rural development”, FAO, Rome, 2000, Environment and Natural Resources Working Paper No. 2.
[4] D. Feldman, G. Barbose, R. Margolis, R. Wiser, N. Darghouth and A. Goodrich, "Photovoltaic (PV) Pricing Trends: Historical, Recent, and Near-Term Projections", SunShot U.S. department of Energy (2012)

[5] J.C. Hernández, A. Medina and F. Jurado, "Optimal allocation and sizing for profitability and voltage enhancement of PV systems on feeders”, Renewable Energy, Vol. 32 (2007) pp. 1768-1789.

[6] M.G. Villalva, J.R. Gazoli, and E.R. Filho, "Comprehensive Approach to Modeling and Simulation of Photovoltaic Arrays", IEEE Transactions on Power Electronics, Vol. 24, N. 5, (2009).

[7] Resolución de 24 de septiembre de 2013, de la Dirección General de Política Energética y Minas, por la que se revisa el coste de producción de energía eléctrica y las tarifas de último recurso a aplicar a partir de 1 de octubre de 2013. BOE Martes 1 de octubre de 2013.

[8] Ley 24/2013, de 26 de diciembre, del Sector Eléctrico. BOE Viernes 27 de diciembre de 2013

[9] A. Chaurey and T.C. Kandpal, "Assessment and evaluation of PV based decentralized rural electrification”, Renewable and Sustainable Energy Reviews, Vol. 14 (2010), pp. 2266-2278.

[10] M.A. Eltawil and Z. Zhao, "Grid-connected photovoltaic power systems: Technical and potential problems-A review", Renewable and Sustainable Energy Reviews, Vol. 14 (2010), pp. 112-129.

[11] H. Jimenez, H. Calleja, R. González, J. Huacuz and J. Lagunas, "The impact of photovoltaic systems on distribution transformer: A case study”, Energy Conversion and Management, Vol. 47 (2006), pp. 311-321.

[12] EN 50160 "Voltage characteristics of electricity supplied by public distribution systems”. 2001.

[13] Real Decreto 1699/2011, de 18 de noviembre, por el que se regula la conexión a red de instalaciones de producción de energía eléctrica de pequeña potencia

BOE Jueves 8 de diciembre de 2011.

[14] Incentive program for solar storage systems. Solarstromspeicher.http://www.solarwirtschaft.de/speicherprogr amm 